\title{
Corrosion fatigue crack growth mechanisms in offshore monopile steel weldments
}

\section{Oyewole Adedipe ${ }^{1}$, Feargal Brennan ${ }^{2}$, Ali Mehmanparast ${ }^{3}$, Athanasios Kolios ${ }^{4}$, Isaac Tavares 5}

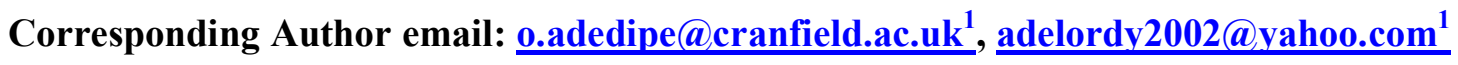

Other Authors email: f.brennan@cranfield.ac.uk ${ }^{2}$, a.mehmanparast@cranfield.ac.uk ${ }^{3}$, a.kolios@cranfield.ac.uk ${ }^{4}$, Isaac.Tavares@centrica.com ${ }^{5}$

\section{1,2,3,4 Offshore Renewable Energy Engineering Centre, Cranfield University, Bedfordshire MK43 OAL, United Kingdom}

${ }^{5}$ Centrica Renewable Energy Limited, Windsor, United Kingdom.

\begin{abstract}
Offshore structures are generally fabricated of welded joints, which are considered as potential spots for crack initiation due to the degree of stress concentrations imposed by the weld geometry and the effects of residual stresses introduced by welding processes. There are significant numbers of the current and anticipated offshore installations coupled with the use of newer materials and fabrication techniques. It is therefore important to understand the crack growth mechanisms in these structures accompanied with the effects of mean or residual stresses for a safe estimation of their service lives. In this paper, crack growth results of HAZ and weld materials similar to those used for offshore installations are presented. Tests were conducted in air and in simulated free-corrosion conditions at loading frequencies of $0.3 \mathrm{~Hz}$ in seawater, $5 \mathrm{~Hz}$ in air and at loading ratios of $0.1,0.5$ and 0.7 . Results showed that crack growth rates were influenced by mean stresses, materials microstructure accompanied by welding procedure and environment. Crack growth results showed good agreement when compared with those obtained from other steels used for offshore structures.
\end{abstract}

Keywords: Crack growth rates, free-corrosion; HAZ; weld; mean stress.

\section{Nomenclature:}

$\begin{array}{ll}a & \text { crack length } \\ B & \text { specimen thickness } \\ W & \text { specimen width } \\ \Delta K & \text { stress intensity factor range } \\ \Delta P & \text { applied cyclic load range }\end{array}$




\section{Introduction}

There has been a significant increase in the use of medium strength steels for offshore structures such as oil and gas platforms, and structures for renewable energy applications. These structures experience millions of load cycles in service and are also exposed to harsh marine environments, which may result in corrosion fatigue failures if inspection and maintenance strategies are not carefully deployed. Offshore structures are fabricated from welded steel sections and due to the phase changes, which occur during welding, there are possibilities for weld induced residual stresses which can significantly influence the degree of mean stresses under cyclic loading. Several sources of mean stresses have been classified in the literature as stresses due to dead weight loading, weld induced stresses and residual stresses accompanied by fabrications. ${ }^{1}$ The phase changes which occur during welding may influence not only the microstructure of the material but also the pattern of crack growth such as crack branching. This has been described by Xiong and $\mathrm{Hu}^{2}$, as crack closure induced crack propagation which resulted in higher resistance to crack growth in Q345 steel.

Studies relating to corrosion assisted crack growth in representative steel materials used for offshore monopile fabrications have shown some appreciable level of importance towards the need for the structures to satisfy their design requirements. Recently, some interesting results were published on corrosion fatigue crack growth in parent material ${ }^{3}$ and few results were presented on crack growth behaviour in the heat affected zone (HAZ) materials at lower stress ratios. ${ }^{4}$ These results have shown that crack growth rates have been enhanced in seawater that in air regardless of the material types. However, Adedipe et al. ${ }^{5}$ mentioned that corrosion fatigue damage mechanisms may not be adequately understood using only parent material for testing. Due to welding induced residual stresses in HAZ and weld materials, newer material, and plate thickness similar to those used in structures for renewable energy applications, accompanied by specimens that are designed for through thickness crack growth measurements. ${ }^{4}$ It is therefore important to include the crack growth behaviour in HAZ and weld material in estimating the fatigue lives of such structures in service.

The available data in the literature on fatigue crack growth in weld and HAZ materials were not obtained from the type of material and specimen fabrication procedure described in 4 . These include the data published in 6-9. Crack growth rates in weld and HAZ materials have been attributed to several factors. In Thompson and Fukuda et al.'s works, ${ }^{6,7}$ crack growth rates in HAZ and weld materials fabricated from BS4360 50D steel were attributed to hardness variation between parent, HAZ and weld materials. However, in Healy et al. and Trudel et al. works, ${ }^{10,11}$ crack growth results were explained with respect to preferred crack growth direction accompanied with microstructure variations in the materials, while in 2,8 , 9,12 , crack growth behaviour in weldments were related to residual stresses induced crack closure. Further explanations can be found in 5. Mean stress effects on crack growth rates have been described as the ratio of the maximum to the minimum stresses used for testing. ${ }^{13}$ However, it was mentioned by Burnside et al. ${ }^{14}$ that mean stress effects on crack growth rates in 50D steel depend on material, environment and crack growth region. This can be argued considering the investigations that have shown different crack growth behaviour in similar materials with respect to increasing mean stresses. ${ }^{15-17}$ Thorpe et al. ${ }^{15}$ found that at free- 
corrosion potential, crack growth rates in BS 4360 50D steels were significantly enhanced as the mean stress was increased from 0.5 to 0.7 . However, Appleton ${ }^{17}$ found that there was no marked effect of increasing mean stress in seawater environment. The differences in temperature and seawater environments have been suggested as the possible reasons for the crack growth behaviour in the materials. ${ }^{5}$ The effects of stress ratio have also been reported to have appreciable influence on crack growth rates in X70 pipeline steels in seawater ${ }^{18}$. However, the results reported in 15-18 were obtained from parent plates.

Irrespective of the costs involved in conducting crack growth tests at higher stress ratios, it is still important to fully understand the crack growth mechanisms in structures that are subjected to high mean stress particularly in thicker plates with dimensions close to those used for monopile fabrications. This is to represent the loading conditions similar to those encountered in service as close as possible. In simulating tensile residual stresses in welds, high stress ratio tests such as R-ratio of 0.5 or higher have been suggested by Havn and Osvoll. ${ }^{19}$ However, this assumption may be limited to near surface tensile residual stresses, but for a through thickness case, the crack growth behaviour may be different due to the overall magnitude of the residual stresses accompanied by the welding procedure. Although, offshore support structures particularly those used for renewable energy applications are now being manufactured using improved welding procedures and design methodologies, but it must be mentioned that the effects of residual/mean stresses in welded structures cannot be eliminated completely due to their complexities. Therefore, it is important to study the fatigue crack growth behaviour in these structures with respect to mean stresses so that existing database can be updated and results that may assist the development of new offshore design standards can be generated. It has been established that limited data have been obtained from weld and HAZ materials extracted from newer types of steels that are used for monopile fabrications, ${ }^{5}$ especially for tests conducted on HAZ materials at higher stress ratios. Apart from the ones that are discussed earlier, some HAZ data were obtained by Mecozzi et al. ${ }^{20}$ at lower stress ratios and therefore may not representative of high mean stress conditions.

In this paper, the fracture mechanics approach is employed to study the crack growth rates in weld and HAZ materials that are fabricated from monopile steels in air and simulated freecorrosion environments. Results are presented with respect to high mean stresses in HAZ and are compared with those obtained from parent and weld materials. Interpretation of the results with respect to microstructure examination of the crack path, fractogaphic analysis of the fracture surface and the variations in hardness values of the materials were also achieved.

\section{Material and specimens extraction}

The material used for testing was a $90 \mathrm{~mm}$ thick welded plate manufactured fromS355J2+N steel. The welding was carried out in accordance with the DNV-OS-C401 recommendations using the SWA-Twin/Tandem-twin process and a $4 \mathrm{~mm}$ filler material designated as S466 FB S3Si. In order to ensure that the direction of crack growth in circumferential welded monopile support structures is reproduced as close as possible, a methodology was developed in Cranfield University for the extraction of the specimens that are used for testing. Three slices of $10 \mathrm{~mm}$ thick specimens which encompass the welded area were machined from the 
edges and the middle sections of the plate in order to establish uniform HAZ and weld dimensions; and for polishing and etching. Grinding of the specimens was achieved using 120, 240 and 1200 grit silicon carbide abrasive papers in ascending order, while the polishing was carried out using the polisher cloth of the appropriate size mounted on the rotating wheel of the Metaserv polishing machine. The polishing was accompanied with the applications of alcohol, diamond paste and colloidal master polisher until a surface finish of $0.5 \mu \mathrm{m}$ was achieved. The extracted slices were etched by applying a $2 \%$ Nital solution in order to reveal the weld runs and the HAZ. After characterising the geometry and dimensions of the weld region in three slices extracted from the welded plate, $16 \mathrm{~mm}$ thick compact tension, CT, specimens were designed according to the specifications set out in the ASTM E64 $7^{21}$ and extracted from the plate, with their notches perpendicular to the rolling direction of the plate. The dimensions of the specimens have been given in 3. The specimens' notches were prepared by spark erosion and were positioned at the HAZ and weld areas of the plate as shown in Figure 1. Further details can be found in 22.

\section{Experimental procedures}

All the crack growth tests were carried out as recommended in the ASTM E647 using two $100 \mathrm{kN}$ capacity servo-hydraulic fatigue testing machines. The tests were carried out at loading frequencies of $0.3 \mathrm{~Hz}$ in seawater, $5 \mathrm{~Hz}$ in air and at loading ratios of $0.1,0.5$ and 0.7 . The reason for the choice of the loading frequency used for testing, particularly in seawater was subject to the frequency sensistivity analysis that was conducted in a previous study. ${ }^{3}$ Crack lengths were measured in air using digital camera and in seawater using back face strain (BFS) and direct current potential drop (DCPD) techniques. The seawater used for the investigations was prepared according to the ASTM D1141. ${ }^{23}$ Details of the experimental procedure have been provided in 3 and 4 including the method used to determine crack lengths from back face strain readings. A test method, which was an extension of the sinusoidal waveforms that are commonly used for fatigue testing, was developed using the wavematrix software and was applied for fatigue crack propagation testing. The method tagged 'loop type waveform' in this paper was developed to allow stable strain gauge readings during the seawater tests so that reliable crack length measurements could be determined.

In the loop type waveform, each loop consists of four steps. The steps are repeated a number of times based on the anticipated number of cycles for the test and each of the waveforms has a start and end envelope of 20 seconds. The number of cycles in each loop is a subject of the number of desired data points with respect to the total number of cycles for the tests. This was based on trial tests. In step one, the waveform was programmed to ramp to the test minimum load at duration of 20 seconds, while in step two, the sinusoidal waveform was applied at the desired number of cycles with respect to the defined start and end envelopes respectively. In step three, the wavematrix was programmed to ramp to the test mean load to allow measurements to be taken from the strain gauge and DCPD, while in step four, the wavematrix was defined to hold at the mean load for 20 seconds to allow enough time for measurements. After step four, the counter would return to step one to commence a new loop. 
After testing, the macro examinations of the crack directions were conducted using the Nikon SMZ745T microscope equipped with an AxioCam ERC5S camera, while the micro examinations were conducted using the Nikon eclipse ME600 optical microscope with magnifications X5 and X20, respectively. Analysis of the fracture surfaces was conducted on selected areas using the Philips XL 30 SFEG Oxford EBSD system at magnifications X200, X1000 and X4000. Hardness tests were carried out using a load of $200 \mathrm{~g}$ on the Zwick computer assisted Vickers micro hardness tester with diamond indenters. Hardness measurements were taken in two sets; from the parent material to weld material and along the HAZ.

\section{Fatigue crack growth analysis}

Crack growth rates were determined from the results of crack lengths and number of cycles using 7-point incremental polynomial method. Cyclic crack tip stress intensity factor range $\Delta K$ was determined by the function of the form: ${ }^{21,24}$

$\Delta K=\frac{\Delta P}{B \sqrt{W}} \frac{\left(2+\frac{a}{W}\right)\left(0.886+4.64\left(\frac{a}{W}\right)-13.32\left(\frac{a}{W}\right)^{2}+14.72\left(\frac{a}{W}\right)^{3}-5.6\left(\frac{a}{W}\right)^{4}\right)}{\left(1-\frac{a}{W}\right)^{1.5}}$

Where;

$\Delta K$ is the stress intensity factor range, $\Delta P$ is the applied cyclic load range, $\mathrm{B}$ is the specimen thickness, $\mathrm{W}$ is the width of the specimen and $a$ is the crack length.

\section{Results and discussions}

Fatigue crack growth tests on different specimens were conducted under the loading conditions specified in Table 1.

\subsection{Fatigue crack growth rates in air and seawater at an R-ratio of 0.1}

The fatigue crack growth rate per cycle obtained from the tests performed at R-ratio of 0.1 in HAZ in air are correlated with the stress intensity factor range and the results are shown in Figure 2. It can be seen that the crack growth curves are similar over the entire $\Delta K$ tested, resulting in bi-linear relationships. However, it can be seen that test 3 produced a steeper crack growth curve at lower $\Delta K$ range compared to the other two tests. Analysis of the crack length versus number of cycles revealed a difference of approximately 190,000 cycles between test 1 and tests 2 and 3. From metallographic examination of the specimen surfaces, it was observed that the starter notch tip of specimen 3 was aligned in the coarse grain region of the HAZ close to the weld material, while in specimens 1 and 2, the notch tips were positioned at the middle regions of the HAZ. Therefore, the difference in loading cycles would have been influenced by different crack initiation sites, propagation pattern, variations in microstructure along the crack paths and the degree of crack branching during propagation. Since cracks initiate at the weld HAZ and propagate in the unaffected parent material, ${ }^{25}$ it is expected that the degree of crack branching towards the parent material would be more if the cracks initiate near the weld compared to near the parent material; and this may be 
responsible for the difference in loading cycles. Also, crack deviation from the coarse grain region towards the region closer to the parent material suggests that crack deviation was a factor of the region having a lower resistance to crack growth. A similar crack branching phenomenon accompanied with crack closure and higher crack growth resistance was also reported in weld materials extracted from Q345 steel. ${ }^{2}$ Interpretation of the results with metallographic examination of the crack surfaces will be discussed further in a later section.

It can be seen from Figure 2 that there is no marked difference in the curves particularly at higher $\Delta K$; which provides an appreciable level of repeatability in the experimental data. The delayed crack growth particularly at lower $\Delta K$ followed by the accelerated crack growth as the crack propagates has been explained by crack closure induced by mean or compressive residual stresses ahead of the crack tips. ${ }^{2,4,8,9}$ In Austin's work, ${ }^{1}$ it was mentioned that the damaging tensile portion of residual stress field in welded plate is approximately a quarter of the plate thickness such that the beneficial (i.e. compressive) segment of the stress field is the mid-section of the plate. However, from the data plotted in Figure 2, the transition from the delayed to the accelerated crack growth regime occurred at $\Delta \mathrm{K}$ less than $19 \mathrm{MPa} \sqrt{m}$, a point where the crack length was approximately $11.25 \mathrm{~mm}$ from the notch and about $47.5 \mathrm{~mm}$ through the thickness of the weld plate. Considering the specimens' orientation as schematically shown in Figure 1, this depth was found to be approximately at the mid-section of the $90 \mathrm{~mm}$ plate where the specimens were extracted from. Therefore, the crack growth behaviour of the HAZ materials in air (Figure 2) appears to be consistent with the explanations given by Austin and may be used to interpret the data.

The crack growth rates in HAZ materials in air and seawater are compared in Figure 3. It can be seen that the seawater curves are similar over the $\Delta \mathrm{K}$ ranges tested. Crack growth rates were found to be slightly higher in the seawater test 2 than in test 1 but the difference was insignificant. The type of crack growth patterns that were obtained in the HAZ materials in air was not evident in seawater probably due to the time dependent behaviour of corrosion $\Omega$ fatigue damage and the interaction of the crack tip with the seawater environment compared with the fatigue crack growth mechanisms in air which is considered to be purely mechanical. Since residual stresses are released as fatigue crack progresses, their effect under a corrosive environment may be marginal, thus leading to the environment being more dominant in seawater compared to residual stresses. However, this proposal was only limited to the observed crack growth behaviour of the HAZ in seawater. Also, due to microstructural changes in the HAZ and weld materials, their corroded surfaces were more severe than in the parent material tested under the same environmental and loading conditions. Therefore, it may also be implied that crack growth rates in the HAZ materials are significantly influenced by these microstructural variations, accompanied by rates of material removal.

Crack growth rates were found to be higher in seawater than in air over the range of $\Delta K$ examined. The Paris-law constants, $C$ and $m$, derived from the line of best fits through the mean data in air and seawater are presented in Table 1. It can be observed that the seawater environment has enhanced the fatigue crack growth rate per cycle by an order of magnitude. At lower $\Delta K$, below $15 \mathrm{MPa} \sqrt{m}$, crack growth rates were found to be twice higher in seawater 
than in air. Beyond the $\Delta K$ of $15 \mathrm{MPa} \sqrt{m}$, crack growth rates in seawater were approximately five times higher than in air. This was due to the environmentally enhanced crack growth mechanisms in seawater which are expected to be significant at higher crack opening displacement. However, at higher $\Delta K$, crack growth rates in seawater were four times higher than in air. It can also be observed in Figure 3 that at higher $\Delta K$, the seawater curves have similar slopes to those obtained in air.

\subsection{Fatigue crack growth rates in air and seawater at different $\boldsymbol{R}$-ratios}

In order to understand the effects of mean stress on crack growth rates in the HAZ material and to eliminate the possible effects of residual stress induced crack closure ${ }^{4}$ which had been used to explain the bi-linear crack growth relationships observed in the tests on HAZ material in air shown in Figure 2, some tests were conducted in air at R-ratios of 0.5 and 0.7 . The results are compared with the mean data of those obtained at R-ratios of 0.1 in Figure 4. It can be seen that for tests conducted at higher R-ratios the bi-linear relationships that were evident at R-ratios of 0.1 are absent. The implication of this is that for tests conducted at higher stress ratios, crack closure effects are not significant due to the degree of crack tip opening. A similar mechanism was reported by Trudel et al. ${ }^{26}$. It can also be observed from the figure that the crack growth responses at R-ratios of 0.5 and 0.7 are similar, which implies that the effects of mean stresses are not significant in air. It can be seen in Figure 4 that lower $\Delta K$ values were obtained at an R-ratio of 0.5 compared to those obtained at an R-ratio of 0.1 , due to the effects of load range. However, two effects were revealed from the comparison made with the R-ratio of 0.1 tests; first, at all the tested $\Delta K$ ranges, crack growth rates were found to be higher at higher R-ratios than at an R-ratio of 0.1 but this was not more than twice the crack growth rates at an R-ratio of 0.1 and secondly, there were reductions in the $\Delta K$ values at a higher $\mathrm{R}$-ratios compared to the $\mathrm{R}$-ratio of 0.1 test.

In Figure 5, crack growth rates obtained in free-corrosion conditions at $R$-ratios of 0.5 and 0.7 are compared with the mean data of those obtained at an $R$-ratio of 0.1 . Crack growth rates were generally found to increase at higher stress ratios compared to those obtained at an $R$ ratio of 0.1 . It can also be seen that the effect of the test environment accompanied with higher $R$-ratios have marked effects on crack growth behaviour in the materials. At $\Delta K$ between $13 \mathrm{MPa} \sqrt{m}$ and $18 \mathrm{MPa} \sqrt{m}$, crack growth rates were found to be twice higher at an $R$-ratio of 0.7 than at an $R$-ratio of 0.5 ; and approximately four times higher than those obtained at an $R$-ratio of 0.1 . At higher $\Delta K$ ranges, beyond $18 \mathrm{MPa} \sqrt{m}$, the $R$-ratio of 0.7 curve deviated towards the $R$-ratio of 0.1 curve. Similarly, it can be seen that at higher $\Delta K$, the crack growth curve obtained at an $R$-ratio of 0.5 approached the one obtained at $R$-ratio of 0.1 . These trends could be explained in terms of the degree of corrosion debris within the crack accompanied by rates of material removal by corrosion in the HAZ material. In Appleton's work, ${ }^{17}$ the extent of corrosion products in the crack was also reported to be dominant under free-corrosion conditions, thus restricting appreciable access of the corrosive environment to the crack tip.

The effects of higher stress ratios on crack growth rates in air and seawater are compared in Figure 6. Over the range of $\Delta K$ values examined, the crack growth rates in seawater were 
significantly enhanced at higher stress ratios and were found to be in the order of two to three times faster than the equivalent air data obtained at R-ratios of 0.5 and 0.7 , respectively. It can also be seen that the acceleration in crack growth in seawater is more rapid at lower $\Delta K$ values compared to the air data. This was due to the effect of the seawater environment, which is expected to be dominant under a fully open crack, leading to a reduction in resistance to crack growth at lower $\Delta K$. The trends of the data plotted in Figure 6 clearly show the significance of environmental interaction with mean stress effects on crack growth rates in seawater compared to in air.

\subsection{Comparison of fatigue crack growth behaviour in HAZ and parent material}

Crack growth rates at lower and higher $R$-ratios in parent material in air are compared with the HAZ data in Figure 7. At lower values of $\Delta K$, for tests conducted at an $R$-ratio of 0.1 , crack growth rates in parent material were higher than the HAZ data by a factor of 4 , compared to higher $\Delta K$ where crack growth rates in parent material were higher than in HAZ material by a factor of approximately 2 . However, at $\Delta K$ above $25 \mathrm{MPa} \sqrt{ }$, the HAZ and parent material curves are similar and the two curves almost converged. In Figure 7, it can also be observed that the crack growth behaviour in the HAZ material at $R$-ratios of 0.5 and 0.7 are similar to those obtained in parent material at the $R$-ratio of 0.1 . For the cases considered in this paper, this implies that the crack growth data obtained in parent material at an $R$-ratio of 0.1 in air may be used to represent HAZ crack growth behaviour in air at higher $R$-ratios. More experimental data are required to confirm these observations and examine the repeatability of these trends.

The HAZ and parent material seawater data obtained at an $R$-ratio of 0.1 and higher $R$-ratios are compared in Figure 8. It can be observed that at the $R$-ratio of 0.1 the HAZ and parent material crack growth data are similar. However, at $\Delta \mathrm{K}$ below $15 \mathrm{MPa} \sqrt{m}$, crack growth ratesin HAZ material were found to be slightly lower than in parent material, but beyond this point, the crack growth behaviour in both materials were nearly the same. This is similar to the crack growth response in a similar material used for offshore installations. ${ }^{6}$ It appears from the present observation at an $R$-ratio of 0.1 that the material data of parent material in seawater can also be used to estimate the corresponding HAZ crack growth behaviour. However, crack growth rates in parent material in seawater at the $R$-ratio 0.5 were also found to be higher than in HAZ materials tested using the same $R$-ratio; but were found to be similar to those obtained from HAZ material at an $R$-ratio of 0.7 at lower $\Delta \mathrm{K}$. At higher $\Delta \mathrm{K}$, crack growth rates in the parent material were found to be about three times higher than in HAZ material, with the HAZ curves converging with the $R$-ratio of 0.1 ones. Considering the presence of possible weld fabrication defects and HAZ microstructure sensitivity to corrosion assisted fatigue crack growth, crack growth accompanied by deposits of layers of corrosion products within the crack is the most likely explanation of the HAZ crack growth rates at higher $\Delta \mathrm{K}$ in seawater. 


\subsection{Fatigue crack growth rates in weld metal in air and seawater}

Crack growth data obtained from weld material at the $R$-ratio of 0.1 in air and seawater are compared in Figure 9 and Figure 10, respectively. The reasons for generating the weld crack growth data in this work was to examine the possibility for cracks initiating from welds and to also compare crack growth rates in welded zones with those in HAZ and parent material. Therefore the data obtained from weld materials in this work are only limited to tests conducted at the $R$-ratio of 0.1 .

It can be observed from Figure 9 that the crack growth trends are similar. The curves deviated at $\Delta \mathrm{K}$ below $20 \mathrm{MPa} \sqrt{ } \mathrm{m}$ with delayed crack growth rates in test1, beyond which the crack growth behaviour is similar. The crack growth mechanism in the weld materials at lower $\Delta \mathrm{K}$, particularly in test 1 may be due to material variation coupled with possibility of improvement in the weld toughness as a result of grain refinement by the subsequent weld layers. Therefore, in test 1 , the crack may be propagating through the weld region having more resistance to crack growth compared to tests 2 and 3. Microstructure examination of the weld materials' crack surfaces revealed that the degree of crack deviation in an attempt to propagate through a preferred path was marginal compared to what was observed in HAZ material. These observations are shown in a later section.

Crack growth rates in weld materials in air are compared with those obtained in seawater in Figure 10. It can be observed in the Figure that the data trends are similar. Crack growth rates in air were found to be similar to the seawater ones at lower $\Delta \mathrm{K}$ particularly when compared with the weld air tests 2 and 3. This was due to the time dependent mechanism of seawater effect within the crack which is not expected to be dominant at lower $\Delta K$. However, at $\Delta K$ less than $17 \mathrm{MPa} \sqrt{ }$, crack growth rates in seawater were approximately three times higher than in air. Subsequently, crack growth rates in seawater were found to be about five to six times higher than in air. At about the $\Delta \mathrm{K}$ range of $20 \mathrm{MPa} \sqrt{m}$, the seawater curves began to approach the air ones and the resulted crack growth rates were measured to be three times higher in seawater than in air. This can be explained by the effects of the deposit of corrosion products at the crack tip at the higher $\Delta \mathrm{K}$ as previously mentioned.

\subsection{Crack growth comparison with literature data}

Crack growth data obtained from HAZ materials were collected from the literature ${ }^{6-8,20,27}$ and are compared with the present data in Figure 11 and Figure 12. It must be mentioned that the existing corrosion fatigue studies and database that were obtained more than 30 years ago are quite large, however, almost no data had been obtained from S355J2+N steel material used for the present investigation, particularly at higher stress ratios, with respect to the weld plate thickness and tests conditions similar to what is experienced by monopile support structures. In Figure 11, it can be seen that the present data are between those obtained from Coudert and Renaudin, Fukuda et al. and Thompson; ${ }^{6,7,27}$ and those obtained from Mecozzi et al. ${ }^{20}$, while Bertini's $^{8}$ data are below the other data plotted in the Figure. The most likely reason to explain the shift in Bertini crack growth curves to the bottom of the other curves is the differences in the applied test loads. The type of crack growth trend obtained from the 
material used for this work; the delayed crack growth at lower $\Delta \mathrm{K}$ and the transition to a higher crack growth regime at higher $\Delta \mathrm{K}$, were not evident in the other data regardless of some similarities in the crack growth curves. This can be explained with respect to the differences in material, welding sequence, welding procedure, material thickness and specimen geometry etc. Details of the welding procedure, thickness and specimens' geometry of the materials whose data are compared with those obtained from the present materials in Figure 11 can be found in. ${ }^{6-8,20,27}$

The data obtained in free-corrosion conditions are compared with those obtained in the literature in Figure 12. The data that are compared with the present results were mostly obtained under free-corrosion potential. Thompson ${ }^{7}$ observed the possibilities of hydrogen induced crack growth even under a free-corrosion potential.The mechanism of environmental enhancement in crack growth rates in BS4360 50D steel in seawater was also explained by hydrogen embrittlement for all the applied potentials including free-corrosion potential ${ }^{16}$. This implies that crack growth data derived under a free-corrosion potential may not absolutely represent the real effects of free-corrosion conditions on fatigue crack growth, as investigated in previous studies. However, from the comparisons made in Figure 12 it was found that only the data obtained by Fukuda et al. are similar to those obtained from the present HAZ materials. In their work, a loading frequency of $0.133 \mathrm{~Hz}$ corresponding to sea wave frequency was used for testing and it is expected that crack growth rates would be higher than those reported in the present study due to the longer time the crack tip is exposed to the corrosive environment. The probable explanation for this is difference in material with respect to material composition, and mechanical properties accompanied with the type of welding procedure used for fabrication. Thompson's data did not agree with the present data, as shown in Figure 12, probably due to the higher load frequency of $0.5 \mathrm{~Hz}$ used for testing with the intention of reducing the test duration. It should be noted that a higher load frequency in seawater would result in lower crack growth rates due to the shorter crack tip opening time. This had also been proved by Vosikovsky ${ }^{28}$ and in 3 . There is a good agreement between the present HAZ data and those obtained from SE702 as shown in the figure particularly at $\Delta K$ above $14 \mathrm{MPa} \sqrt{ }$. This is also in agreement with the comparisons made for parent material fabricated from S355J2+N and SE702 steels ${ }^{3}$. Mecozzi et al. did not obtain any crack growth results in seawater; their data are therefore not included in the comparisons made in Figure 12.

In Figure 13, the mean data obtained from weld material at the $R$-ratio of 0.1 in air are compared with those obtained by Thompson ${ }^{7}$ and Bertini ${ }^{8}$ for BS4360 50D and C-Mn steels. Bertini's data did not agree with the present data probably due to the differences in the test load range, specimen geometry, material composition and the yield strength of the welded zone that was investigated; which was reported to be $490 \mathrm{MPa}$. However, in seawater (Figure 14), comparisons revealed that the crack growth behaviour of the present data is quite similar to Thompson's data but dissimilar to Bertini's data. When the data were analysed, it was found that Thompson's data were obtained from $20 \mathrm{MPa} \sqrt{m}$ to $50 \mathrm{MPa} \sqrt{m}$, while Bertini's data were obtained from $25 \mathrm{MPa} \sqrt{m}$ to $71 \mathrm{MPa} \sqrt{m}$. The present data were measured at $\Delta K$ between $14 \mathrm{MPa} \sqrt{m}$ to approximately $30 \mathrm{MPa} \sqrt{m}$. This implies that higher test loads were 
used in Bertini's and Thompson's tests compared to this work. Therefore, the data were compared based on the crack growth rates within the range of the present results. These were found to be slightly higher than Thompson's data particularly at $\Delta K$ between $22 \mathrm{MPa} \sqrt{m}$ and $30 \mathrm{MPa} \sqrt{m}$.

\subsection{Comparison of parent, HAZ and weld materials}

The data obtained in air at the $R$-ratio of 0.1 in parent, HAZ and weld materials are compared in Figure 15. Data analysis revealed that crack growth rates were generally higher in parent material than in HAZ and weld materials respectiv It can also be seen that the crack growth trends in HAZ and weld materials are similar particularly at higher $\Delta \mathrm{K}$. However, in free-corrosion conditions, crack growth rates were found to be similar in the three materials, as shown in the Figure 16. There was a slight difference in crack growth rates in parent material and those obtained in the HAZ and weld materials. The material constants resulting from the lines of best fit through the data obtained in parent, HAZ and weld materials are set out in Table 1. The $C$ and $m$ values in parent, HAZ and weld materials are those derived using the mean data. Regardless of the parallel relationships in the crack growth rates in air and seawater at the $R$-ratio of 0.1 , the material constants vary from the parent, HAZ and weld materials. The implication is that the effects of environment and material variation still contributed to the crack growth rates in the materials. However, data analysis generally revealed similarities in crack growth rates in parents, HAZ and weld materials. This was also reported for high strength steels weld and parent material with yield strength between $500 \mathrm{MPa}$ to $600 \mathrm{MPa}^{29}$ It was recommended that suitable screening of the parent material crack growth data may be applied to evaluate the suitability of weldments. In Table 1, the material constants of the higher $R$-ratio tests also vary from parent, HAZ and weld materials. However, it can be observed that the $R$-ratios of 0.5 and 0.7 tests in HAZ have same $m$ values but different $C$ values. This implies that $R$-ratio effects in this case only have a significant effect on $C$ values but marginal effects on $m$ values.

\subsection{Discussion of results with microstructure analysis of the crack path}

The microstructure variation in HAZ material is shown in Figure 17. It can be seen that the crack propagated in the middle region of the HAZ, at the left of the coarse grains and later deviated towards the finer grains closer to the parent material due to its lower resistance to crack growth accompanied by microstructure induced crack growth. Xiong and $\mathrm{Hu}^{2}$ also reported a similar crack branching phenomenon in Q345 steel weldments at lower stress ratios, leading to a reduction in crack growth. Crack branching was also observed in stainless steel welds ${ }^{26}$ and in Healy et al. work ${ }^{10}$, it was found that crack path in the HAZ of CSN3:8 steel was influenced by microstructure. It may therefore be implied that the data presented in Figure 2 (HAZ, air) are also influenced by microstructure variations in the HAZ materials.

The difference in crack path deviation between the HAZ and weld materials is compared in Figure 18. It can be seen that the changes in crack path were more in the HAZ microstructure than in the weld material. This would have also contributed to the difference in crack growth patterns in the two materials. 


\subsection{Discussion of results with the analysis of the fracture surfaces}

The examined fracture surfaces of the specimens tested at $R$-ratio of 0.1 are shown in Figure 19 to Figure 24, including those obtained from parent material. Crack growth results of parent material have been discussed in a previous study. ${ }^{3}$ Analysis of all the fracture surfaces with respect to $\Delta \mathrm{K}$ was not in detail. However, the areas of interest were only examined particularly in the HAZ materials due to the data trend plotted in Figure 2. In parent material in air, the examined fracture surface shown in Figure 19 revealed a mixture of ductile and brittle striation mechanisms.

In HAZ materials, as previously mentioned the change in the slopes of the data plotted in Figure 2 occurred at $\Delta \mathrm{K}$ below $19 \mathrm{MPa} \sqrt{m}$, therefore, the fracture surfaces corresponding to $\Delta \mathrm{K}$ between $18 \mathrm{MPa} \sqrt{\mathrm{m}}$ and $19 \mathrm{MPa} \sqrt{\mathrm{m}}$ were only examined. The results are shown in Figure 20. At $\Delta \mathrm{K}$ of $18 \mathrm{MPa} \sqrt{\mathrm{m}}$, the bottom right of the figure, it can be seen that the degree of fatigue striations are significantly higher than those at the top right of the figure which corresponds to $\Delta \mathrm{K}$ of $19 \mathrm{MPa} \sqrt{\mathrm{m}}$. The amount of striations in the bottom right may be due to the delayed crack growth prior to $\Delta \mathrm{K}$ below $19 \mathrm{MPa} \sqrt{\mathrm{m}}$ and the surface appearance shown at the top right may also be related to the change in slope in Figure 2 prior to transition to the faster crack growth region.

The fracture surface of the weld material tested in air is shown in Figure 21. The surface appearance shows mixture of brittle and ductile striations, which may be due to possible defects introduced during welding and weld in-homogeneity. In seawater, at $\Delta \mathrm{K}$ of $19 \mathrm{MPa} \sqrt{\mathrm{m}}$, the fracture surface of the parent material shown in Figure 22 revealed uniform cracking mechanism particularly at the right of the figure. Some cleavage features of the surface are also evident at the left of the figure accompanied with some corrosion products. The appearance of the fracture surface may be related to a minimum level of corrosion enhanced damage in the parent material's microstructure compared to in HAZ (Figure 23) and weld materials (Figure 24). This implies that fracture surfaces accompanied by the type of striations are material dependent, as mentioned in 30 .

The features of the fracture surfaces of the HAZ and weld materials are shown in Figure 23 and Figure 24. It can be observed that the damage features are significantly enhanced by corrosion compared to in parent material (Figure 22). The degree of the corrosion enhanced damage in the surfaces increased with an increase in $\Delta \mathrm{K}$. At $\Delta \mathrm{K}$ of $20 \mathrm{MPa} \sqrt{\mathrm{m}}$, the crack growth mechanism showed mainly brittle form of failure. The HAZ and weld materials fracture surfaces were also found to exhibit corrosion pits more severely than in parent material. In weld materials (Figure 24), it was also found that the crack propagated by brittle striation mechanisms and some pits are evident as shown in the figure, due to corrosion effects. The implication of this is that both material microstructure variation and environmental factors are responsible for the crack growth mechanisms in seawater.

\subsection{Discussion of results with hardness measurements}

The hardness measurements taken from the parent material are compared with those measured in HAZ and weld zones as shown in the left of Figure 25. It can be observed that 
the hardness values of the HAZ decrease from the weld towards the parent material with a mean hardness value of $209 \mathrm{HV}$. However, in the parent material, the mean hardness value was found to be $200 \mathrm{HV}$. It can also be seen from the right of the figure that the hardness values decrease from the coarse grain to the finer grain microstructure. The data plotted in the figure imply that the crack deviated from the harder region of the HAZ to the weaker region closer to the parent material. The variation in HAZ hardness values was also in agreement with what was reported for a similar material ${ }^{7}$ and in other types of steel. ${ }^{10,11,26,31}$

\section{Conclusions}

The crack growth behaviours in HAZ and weld materials fabricated from S355J2+N steel were investigated in air and in a laboratory simulated seawater environment similar to what is experienced by offshore installations in service. The following conclusions can be drawn from the study.

1. The methodology developed for conducting crack growth tests in seawater has proved reliable. Small-scale specimens extracted from relatively thick weld plate with similar dimensions to those used for monopile fabrications have been used to reproduce the crack growth behaviour in the structures as close as possible.

2. The air tests conducted on HAZ materials at the $R$-ratio of 0.1 revealed delayed and accelerated crack growth at lower and higher applied stress intensity factor ranges respectively, resulting in a bi-linear relationship of the $d a / d N$ versus $\Delta K$ plots. However, at higher $R$-ratios bi-linear crack growth trend was eliminated.

3. Based on the limited test data obtained from this study, HAZ and weld materials showed higher resistance to crack growth than in parent material for tests conducted in air. However, in free-corrosion conditions, crack growth rates in HAZ, weld and parent material were found to be similar.

4. Crack growth rates in HAZ and weld materials were significantly enhanced in freecorrosion conditions, at all the stress ratios studied than in air environment. The HAZ and weld materials showed good resistance to crack growth when compared with other types of steels used for offshore structures.

5. Crack growth rates in HAZ materials were not only influenced by environment, material microstructure accompanied by welding process but by crack closure induced by possible effects of residual stresses.

6. Mean stress effects on fatigue crack growth depend on environment, material and loading conditions. Improvement in welding procedures accompanied with welding sequences can reduce the effects of high mean stress (i.e. damaging tensile residual stress) in offshore structures. 


\section{Acknowledgements}

The authors acknowledge the support of the Offshore Wind Structural Lifecycle Industry Collaboration (SLIC) project managed by Centrica Energy (UK) Ltd and of the Petroleum Technology Development Fund (PTDF), Nigeria who supported the PhD of Oyewole Adedipe.

\section{References}

1 Austin, J. A. (1994) The role of corrosion fatigue crack growth mechanisms in predicting the fatigue life of offshore tubular joints. PhD Thesis, University College London.

2 Xiong, Y. and Hu, X. X. (2012) The effect of microstructures on fatigue crack growth in Q345 steel welded joint. Fatigue Fract. Eng. Mater. Struct., 35, no. 6, 500-512.

3 Adedipe, O., Brennan, F. and Kolios, A. (2015) Corrosion fatigue load frequency sensitivity analysis. Mar. Struct., 42, 115-136.

4 Adedipe, O., Brennan, F. and Kolios, A. (2015) Corrosion fatigue crack growth in offshore wind monopile steel HAZ material. Analysis and Design of Marine Structures $V$, 5th International Conference on Marine Structures, Taylor and Francis Group. 207-212.

5 Adedipe, O., Brennan, F. and Kolios, A. (2016) Review of corrosion fatigue in offshore structures : Present status and challenges in the offshore wind sector. Renew. Sustain. Energy Rev., 61, 141-154.

6 Fukuda, T., Iwadate, T. and Shimazaki, M. (1982) Consideration on the scatter of $\mathrm{COD}$ and fatigue crack propagation characteristics of heavy section $\mathrm{C}-\mathrm{Mn}-\mathrm{V}$ forged steel for offshore structure. Offshore Technology Conference, 109-112.

7 Thompson, J. W. C. (1984) Phenomenological investigation of the influence of Cathodic protection on corrosion fatigue crack propagation behaviour, in a BS 4360 50D type structural steel and associated weldment microstructures, in a marine environment. $\mathrm{PhD}$ Thesis, Cranfield Institute of Technology.

8 Bertini, L. (1991) Influence of seawater and residual stresses on fatigue crack growth in C-Mn steel weld joints. Theor. Appl. Fract. Mech., 16, no. 2, 135-144.

9 Beghini, M. and Bertini, L. (1990) Fatigue crack propagation through residual stress fields with closure phenomena. Eng. Fract. Mech., 36, no. 3, 379-387.

10 Healy, J., Chubb, J. P. and Billingham, J. (1990) Further assessment of cast steel for use in offshore structures. Int. J. Fatigue, 12, no. 3, 191-197.

11 Trudel, A., Lévesque, M. and Brochu, M. (2014) Microstructural effects on the fatigue crack growth resistance of a stainless steel CA6NM weld. Eng. Fract. Mech., 115, 6072.

12 Tsay, L. W., Chern, T. S., Gau, C. Y. and Yang, J. R. (1999) Microstructures and fatigue crack growth of EH36 TMCP steel weldments. Int. J. Fatigue, 21, no. 8, 857864.

13 Adedipe, O., Brennan, F. and Kolios, A. (2016) A relative crack opening time correlation for corrosion fatigue crack growth in offshore structures. Fatigue Fract. Eng. Mater. Struct. 395-411.

14 Burnside, O. H., Hudak, S. J., Oelkers, E., Chan, K. and Dextert, R. I. (1984) Longterm corrosion fatigue of welded marine steels. Ship Structure Committee, Texas.

15 Thorpe, T. W., Scott, P. M., Rance, A. and Silvester, D. (1983) Corrosion fatigue of BS 4360:50D structural steel in seawater. Int. J. Fatigue, 5, no. 3, 123-133.

16 Scott, P. M., Thorpe, T. W. and Silvester, D. R. V. (1983) Rate -determining process 
for corrosion fatigue crack growth in ferrite steels in seawater. Corros. Sci., 23, no. 6, $559-575$.

17 Appleton, R. J. (1985) Corrosion fatigue of a C-Mn steel. PhD Thesis, University of Glasgow.

18 Vosikovsky, O. (1980) Effects of stress ratio on fatigue crack growth rates in X70 pipeline steel in air and saltwater. J. Test. Eval., 8, no. 2, 68-73.

19 Havn T. and Osvoll, H. (2002) Corrosion fatigue of steel in seawater. NACE International Corrosion Conference, no. 02431, 1-11.

20 Mecozzi, E., Lecca, M., Sorrentino, S., Large, M., Davies, C., Gouveia, H., Maia, C., Erdelen-Peppler, M., Karamanos, S. and Perdikaris, P. (2010) Fatigue behaviour of high strength steel welded joints in offshore and marine systems. Final Report EUR 24214EN.

21 ASTM E647 (2008) Standard test method for measurement of fatigue crack growth rates.

22 Adedipe, O. (2015) Integrity of offshore structures. PhD Thesis, Cranfield University.

23 ASTM D1141 (2008) Standard practice for the preparation of substitute ocean water.

24 BS EN ISO 11782-2 (2008) Corrosion of metals and alloys- Corrosion fatigue testingPart 2: Crack propagation testing using precracked specimens.

25 Johnson, R., Bretherton, I., Tomkins, B., Scott, P. and Silvester, D. R. (1978) The effect of sea water corrosion on fatigue crack propagation in structural steel. Paper 15, European Offshore Steels research seminar.

26 Trudel, A., Sabourin, M., Lévesque, M. and Brochu, M. (2014) Fatigue crack growth in the heat affected zone of a hydraulic turbine runner weld. Int. J. Fatigue, 66, 39-46.

27 Coudert, E. and Renaudin, C. (1998) Variable amplitude corrosion fatigue behaviour and hydrogen embrittlement of high strength steels for offshore applications.

International Offshore and Polar Engineering Conference, vol. IV, 116-122.

28 Vosikovsky, O. (1975) Fatigue crack growth in an X-65 pipeline steel at low cyclic frequencies in aqueous environments. Trans. ASME, J. Eng. Mater. Technol., 97, no. 4, 299-304.

29 Healy, J. and Billingham, J. (1997) A review of the corrosion fatigue behaviour of structural steels in the strength range $350-900 \mathrm{MPa}$ and associated high strength weldments. Health and Safety Executive-Offshore Technology Report (OTH 532), Norwich, United Kingdom.

30 Schijve, J. (2003) Fatigue of structures and materials in the 20th century and the state of the art. Int. J. Fatigue, 25, no. 8, 679-702.

31 Callister, D. R. (1987) A study of fatigue crack propagation in quenched and tempered and controlled rolled high strength low alloy (HSLA) steels," PhD Thesis, Cranfield Institute of Technology. 
Table 1 Loading conditions and material constants for parent plate, HAZ and weld materials

\begin{tabular}{lllccl}
\hline Environment & Material & R-ratio & $\Delta \mathbf{P}(\boldsymbol{k N})$ & $\boldsymbol{C}$ & $\boldsymbol{m}$ \\
\hline Air & Parent & 0.1 & 9 & $7.1 \times 10^{-12}$ & 3.0 \\
Air & HAZ & 0.1 & 9 & $7.0 \times 10^{-13}$ & 3.5 \\
Air & Weld & 0.1 & 9 & $5.0 \times 10^{-13}$ & 3.6 \\
Air & Parent & 0.5 & 7 & $2.1 \times 10^{-12}$ & 3.4 \\
Air & Parent & 0.7 & 5.25 & $2.0 \times 10^{-11}$ & 2.6 \\
Air & HAZ & 0.5 & 7 & $7.0 \times 10^{-13}$ & 3.7 \\
Air & HAZ & 0.7 & 5.25 & $2.1 \times 10^{-12}$ & 3.4 \\
Seawater & Parent & 0.1 & 9 & $4.1 \times 10^{-13}$ & 4.2 \\
Seawater & HAZ & 0.1 & 9 & $6.0 \times 10^{-14}$ & 4.7 \\
Seawater & Weld & 0.1 & 9 & $3.0 \times 10^{-15}$ & 5.7 \\
Seawater & Parent & 0.5 & 7 & $3.1 \times 10^{-14}$ & 5.6 \\
Seawater & HAZ & 0.5 & 7 & $8.0 \times 10^{-13}$ & 4.0 \\
Seawater & HAZ & 0.7 & 5.25 & $1.1 \times 10^{-12}$ & 4.0 \\
\hline
\end{tabular}




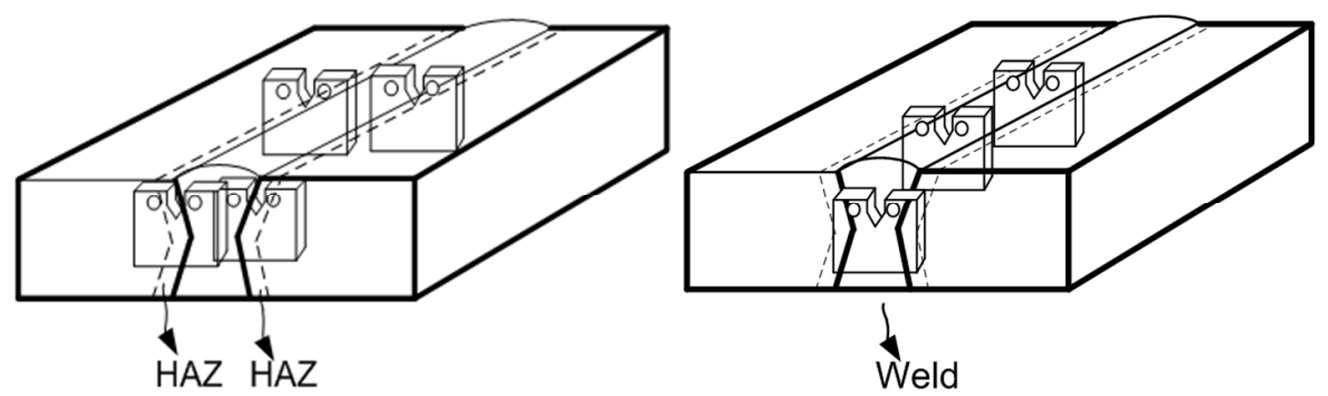

Figure $1 \mathrm{CT}$ specimens extracted from HAZ and weld regions of a $90 \mathrm{~mm}$ thick plate

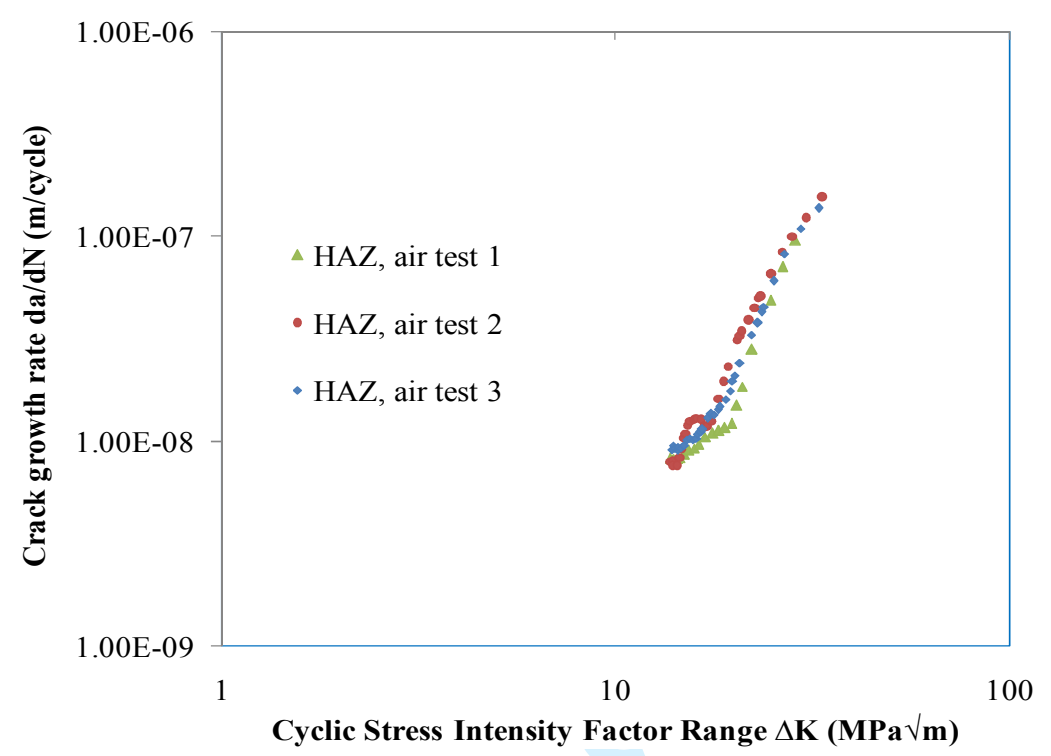

Figure 2 Crack growth rates in HAZ materials in air

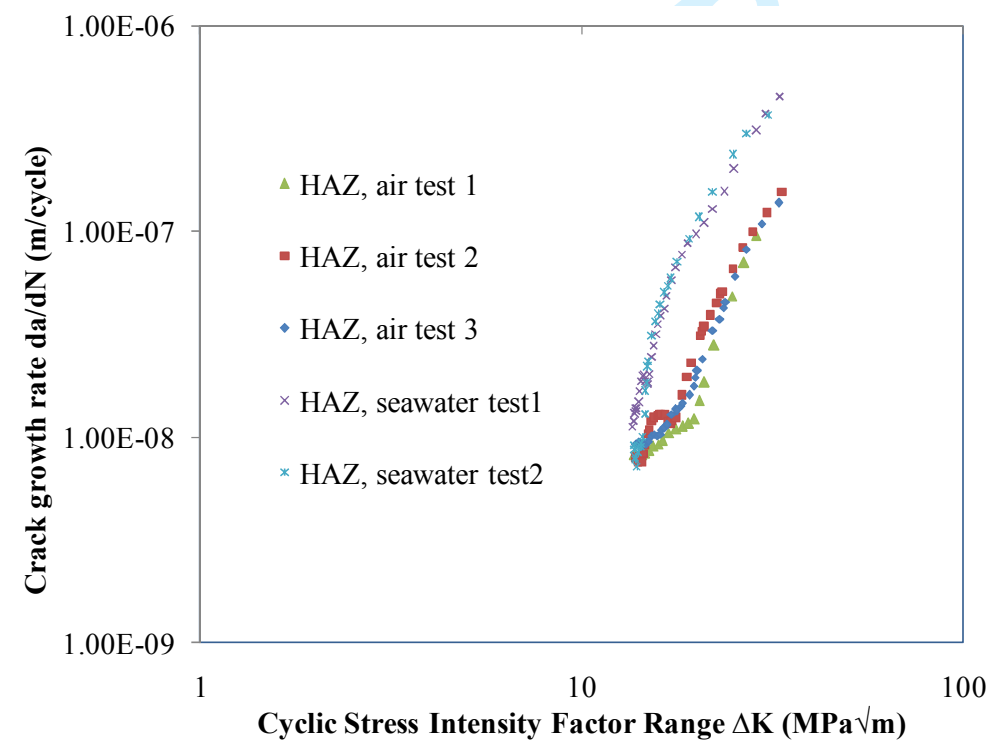

Figure 3 Crack growth rates in HAZ materials in air and seawater 


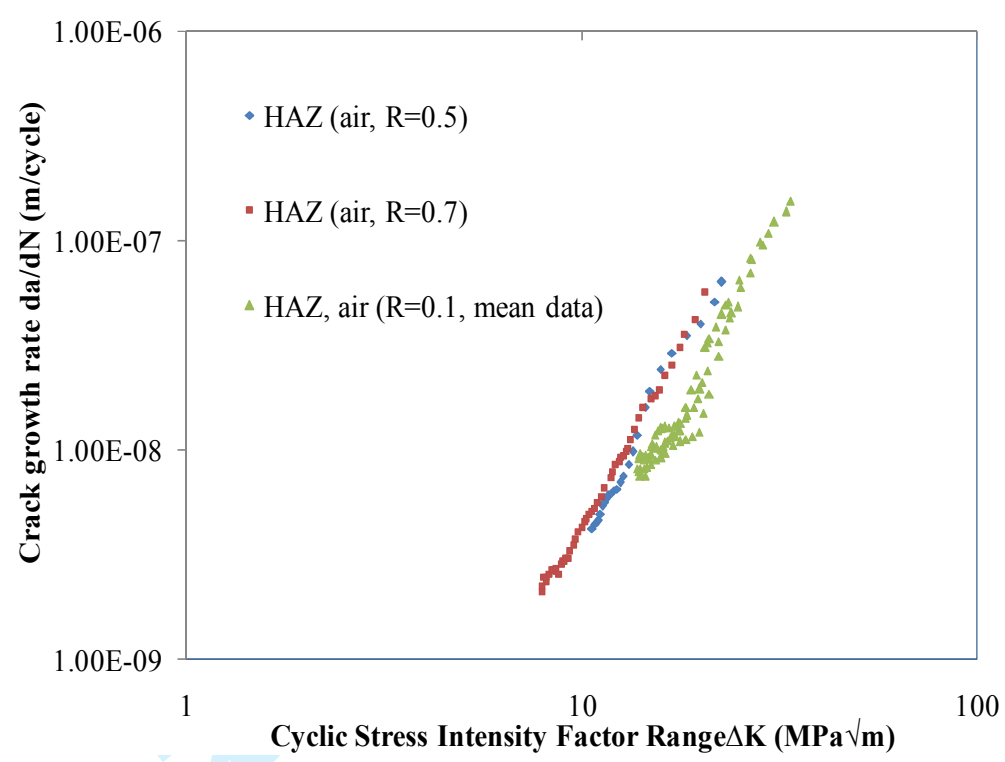

Figure 4 Crack growth rates in HAZ materials in air at R-ratios of $0.1,0.5$ and 0.7

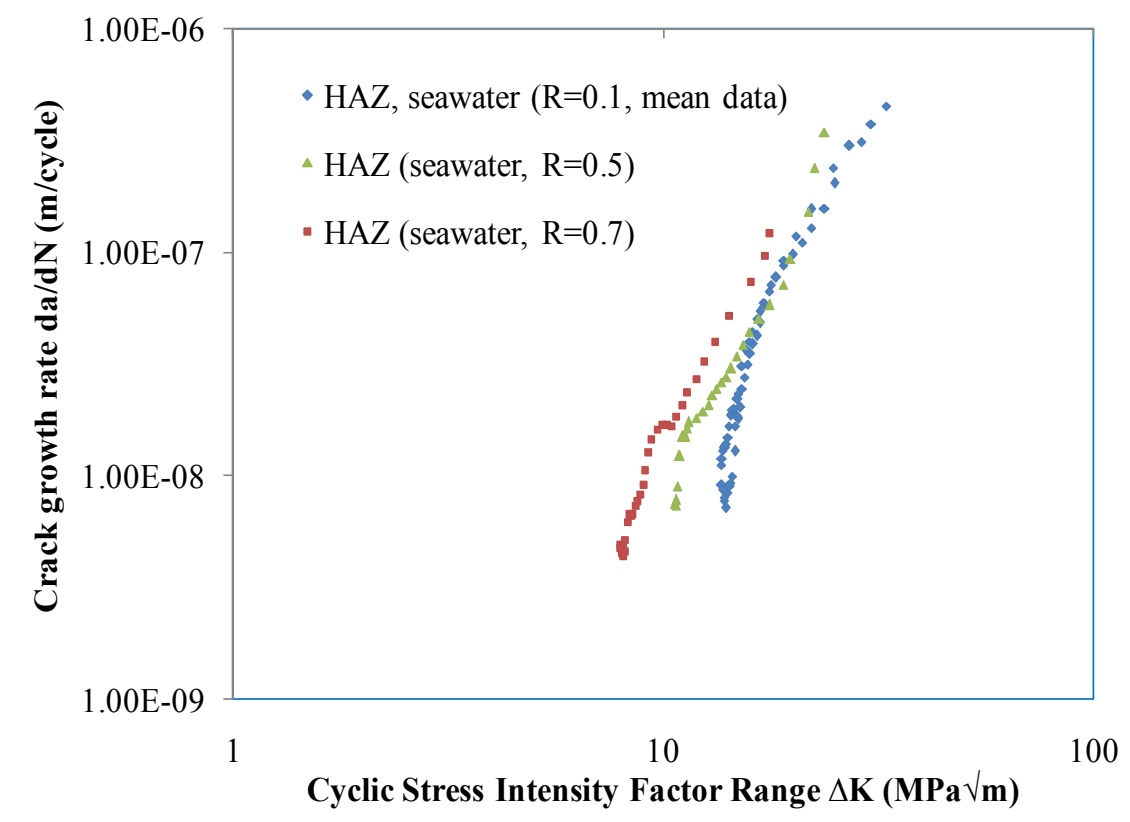

Figure 5 Crack growth rates in HAZ materials in seawater at R-ratios of 0.1 to 0.7 


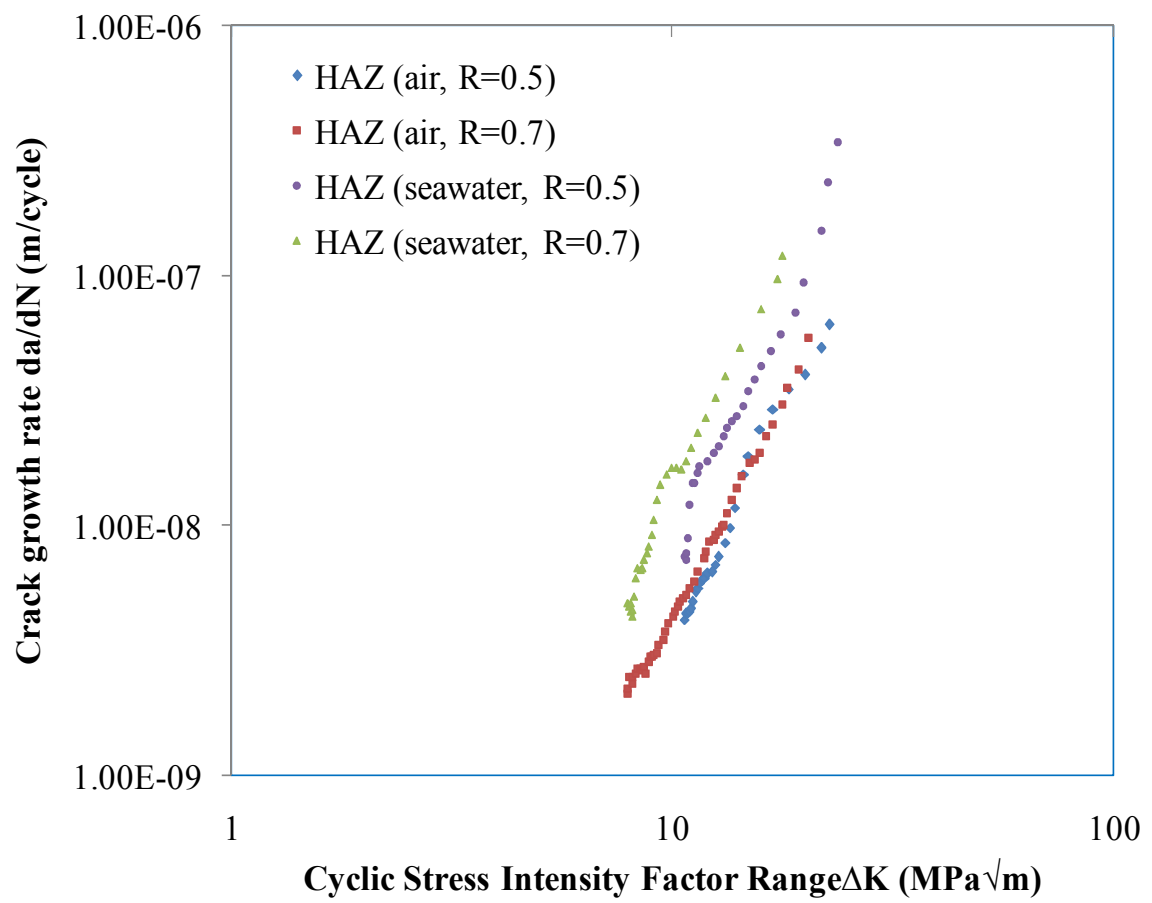

Figure 6 Air and seawater data in HAZ at $R$ ratios of 0.5 and 0.7

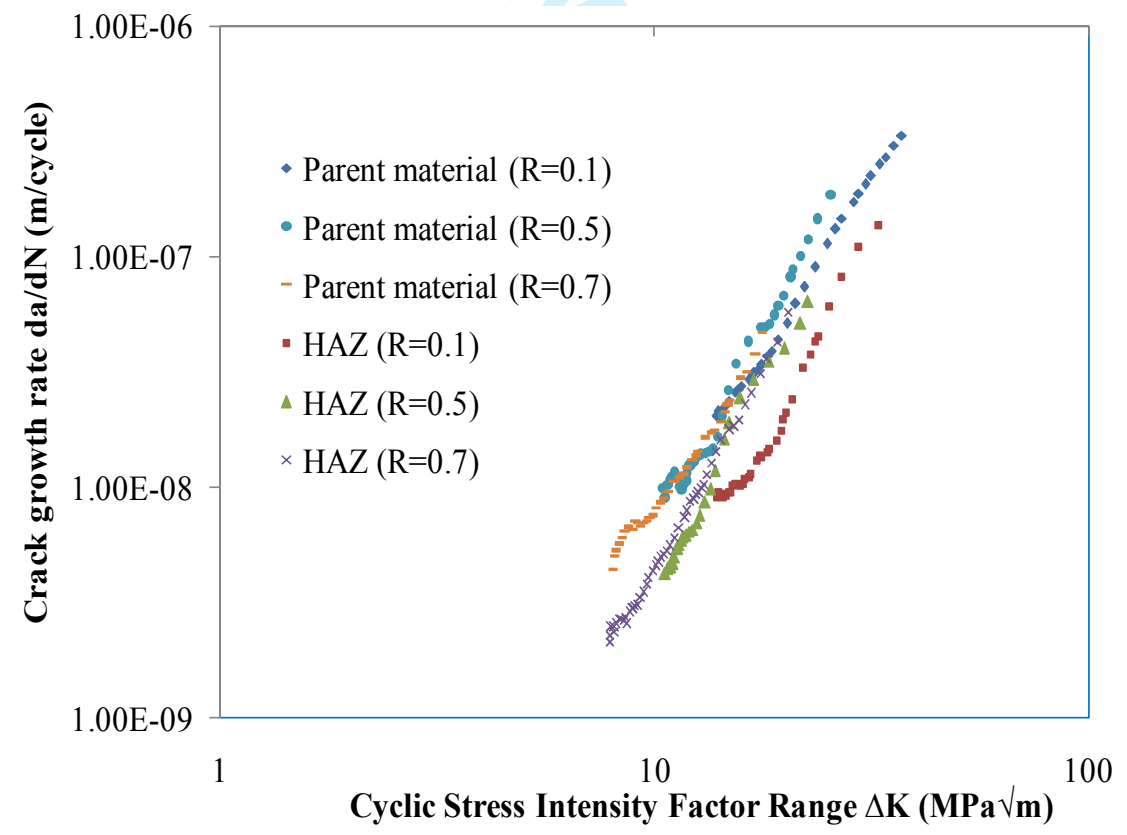

Figure 7 Crack growth data comparison in HAZ and parent material in air 


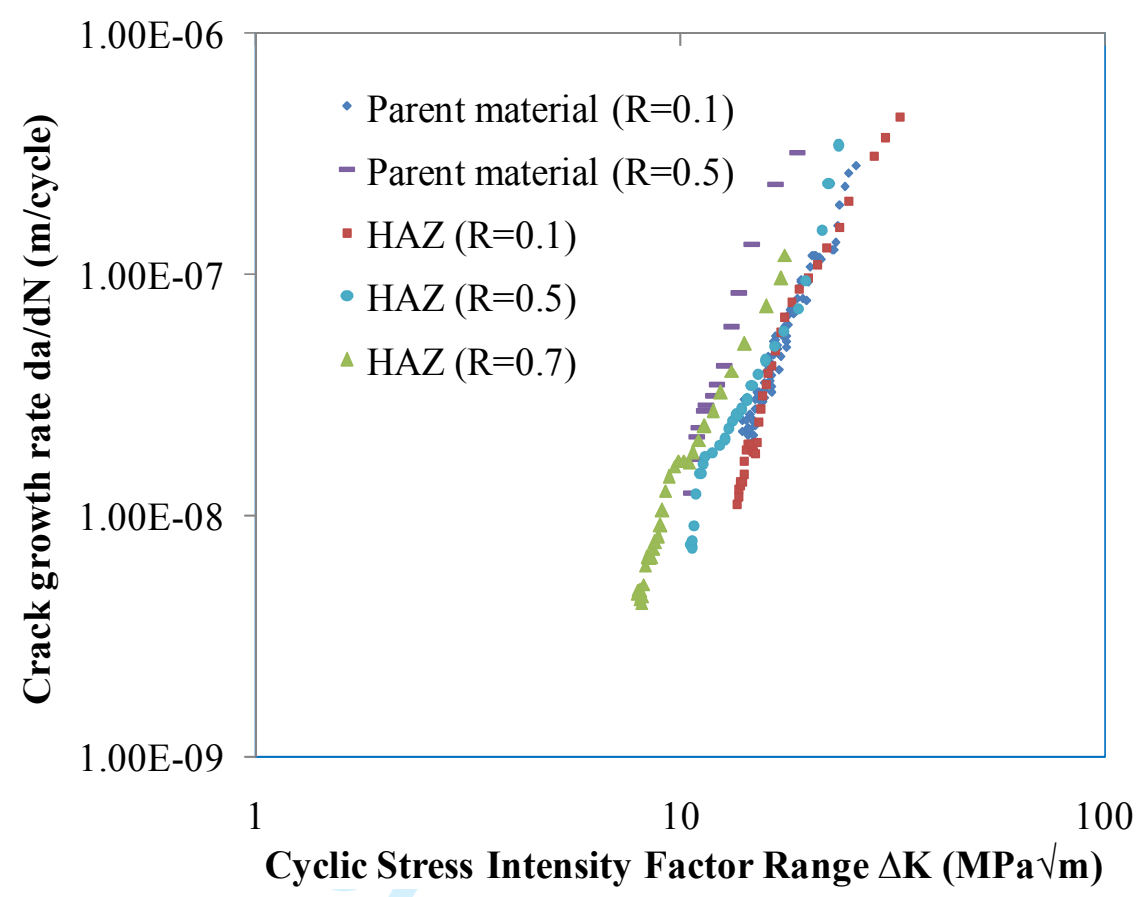

Figure 8 Crack growth data comparison in HAZ and parent material in seawater

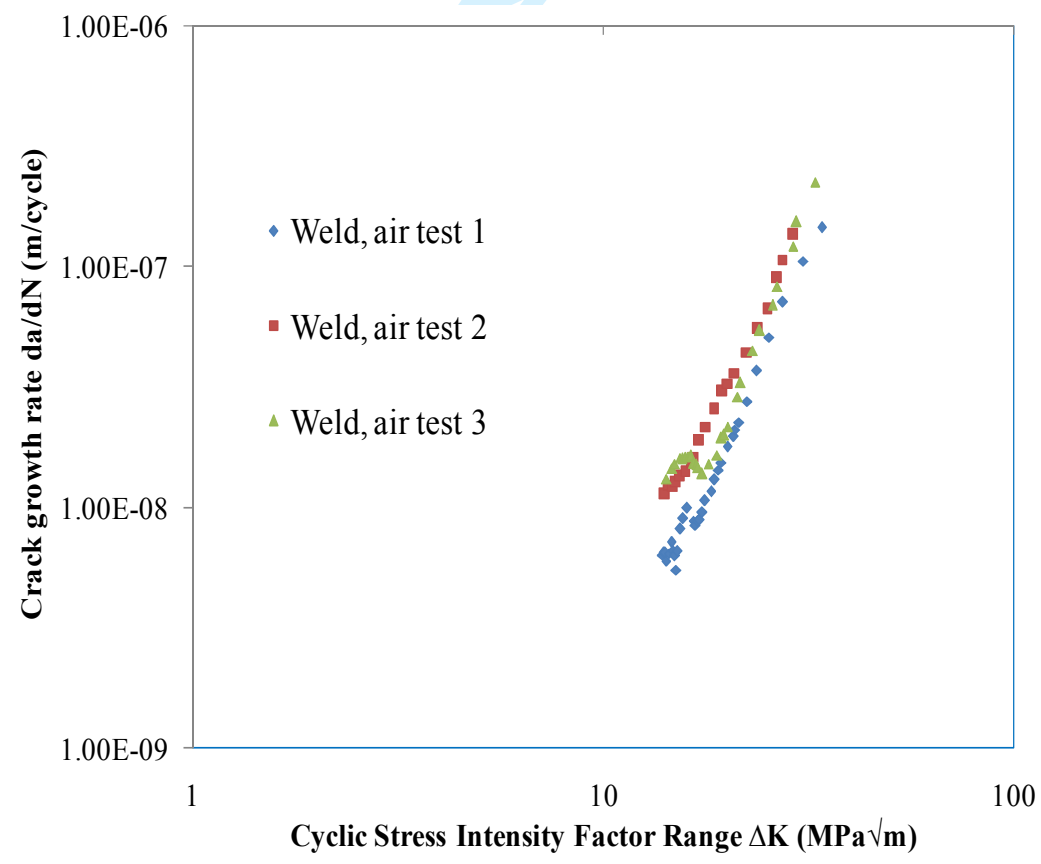

Figure 9 Crack growth rates in weld materials in air 


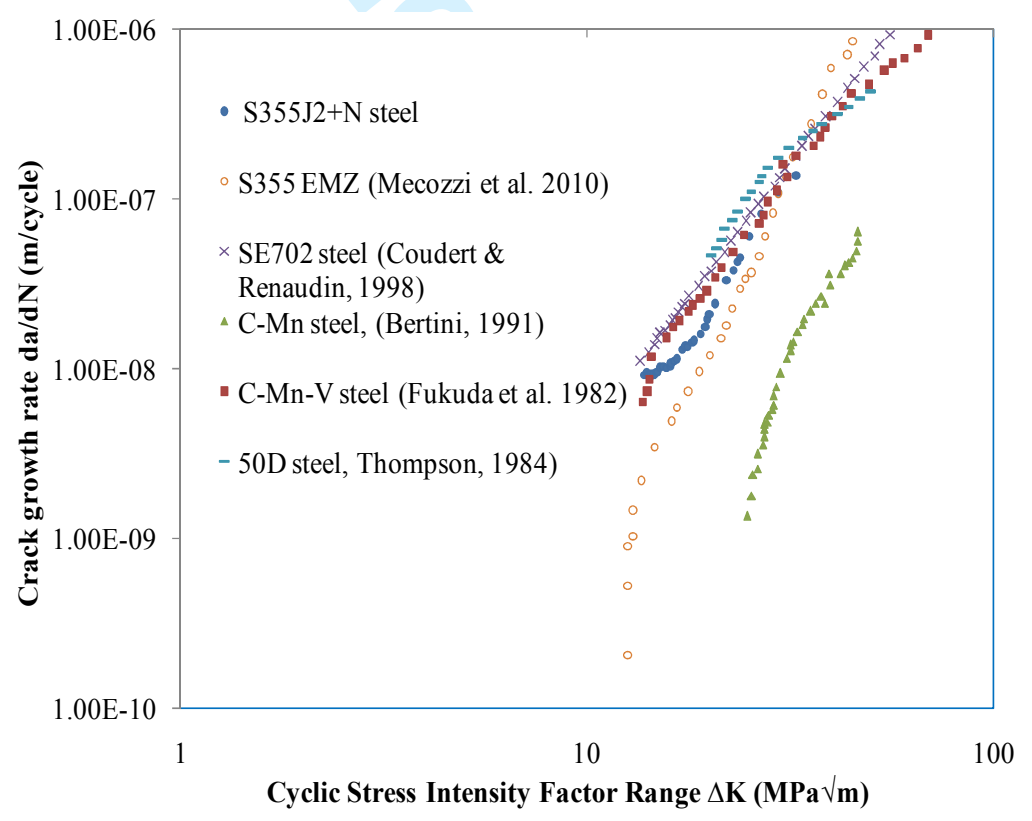

Figure 11 Comparison of crack growth rates in HAZ material in air with literature data 


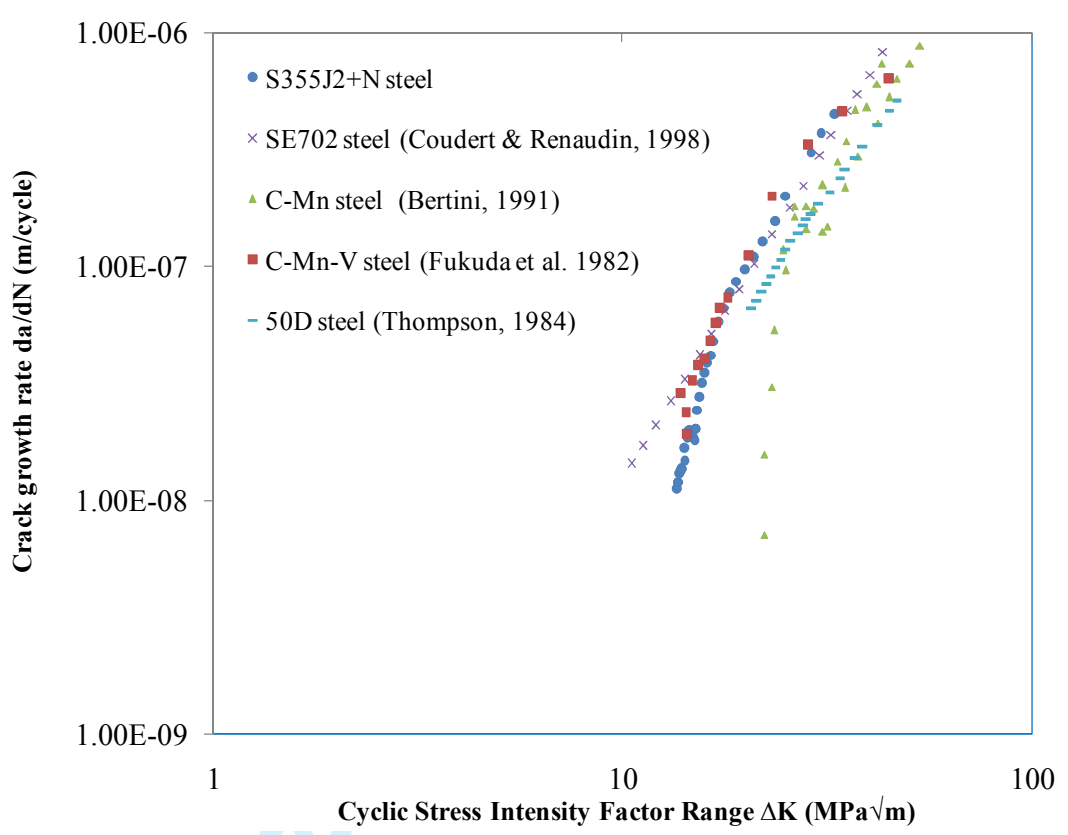

Figure 12 Comparison of crack growth rates in HAZ material in seawater with literature data

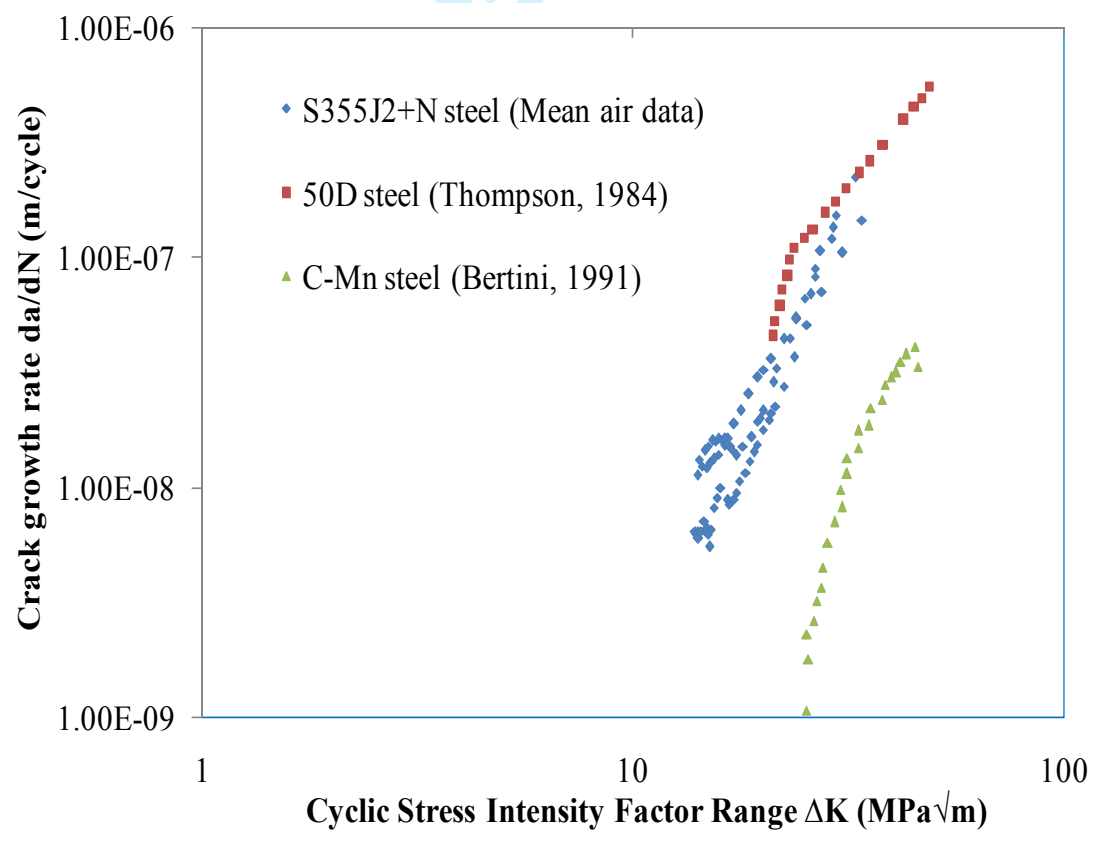

Figure 13 Comparison of crack growth rates in weld material in air with literature data 


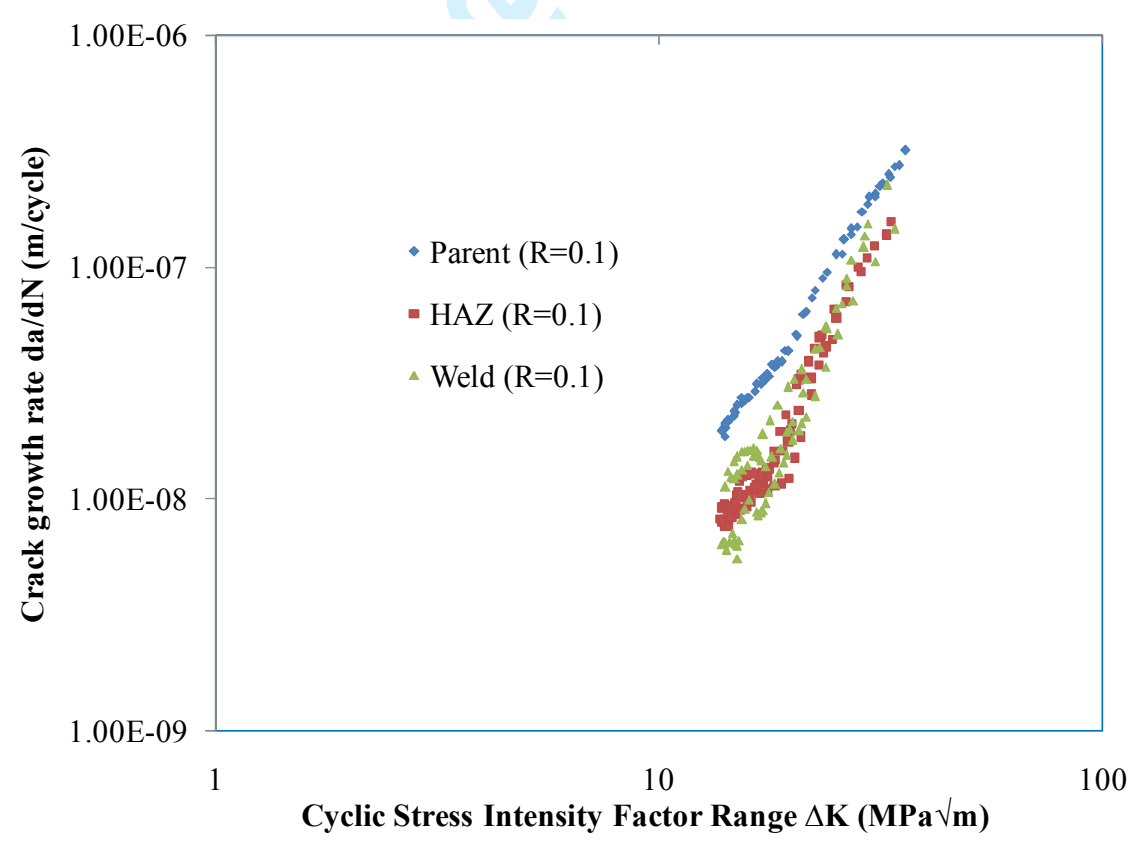

Figure 15 Crack growth rates in parent, HAZ and weld materials in air at an R-ratio of 0.1 


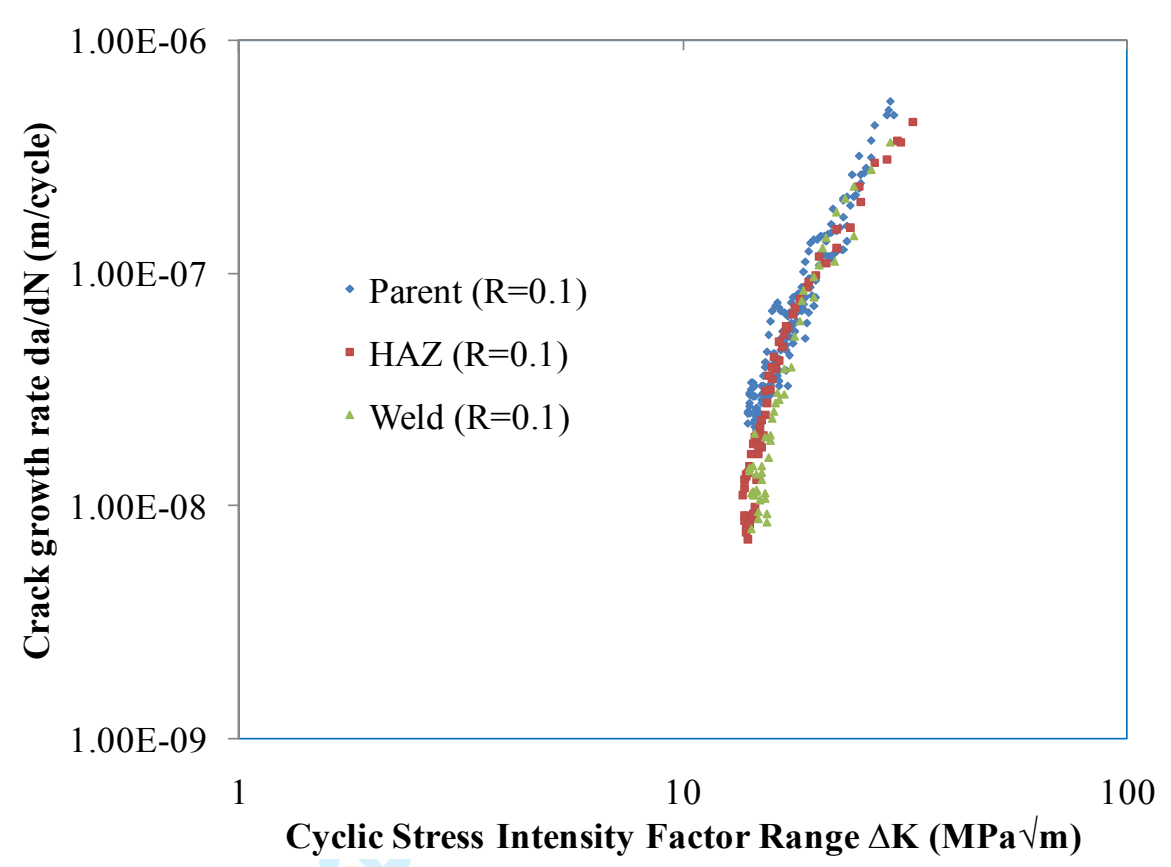

Figure 16 Crack growth rates in parent, HAZ and weld materials in seawater at an R-ratio of 0.1

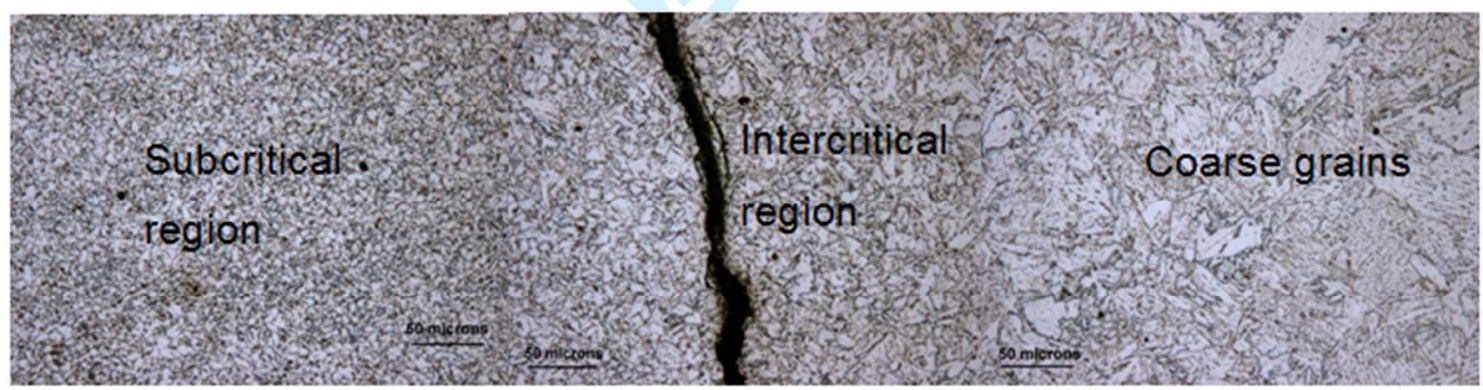

Figure 17 Crack growth in the Intercritical HAZ region (X5)

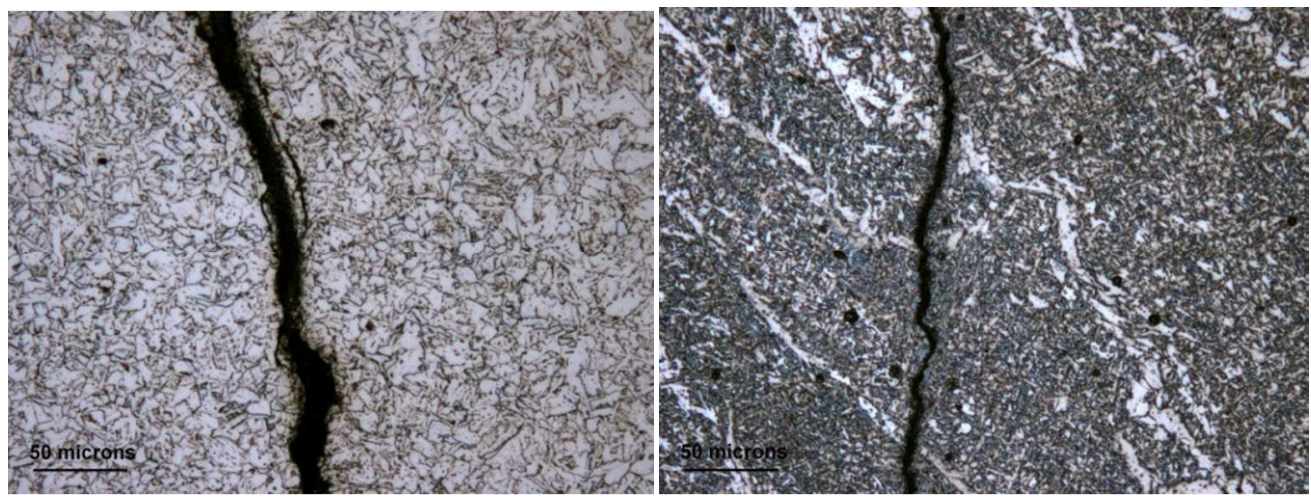

Figure 18 Crack growth pattern in left: HAZ and right: weld materials (X20) 


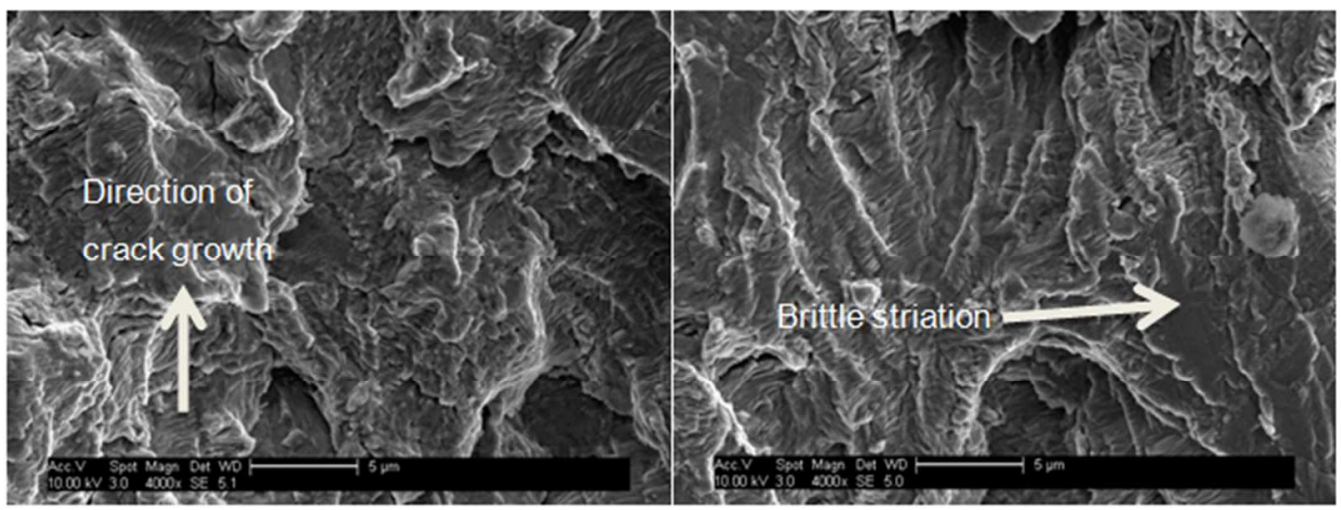

Figure 19 Mixture of ductile and brittle striations in parent material in air at $\Delta \mathrm{K}=20 \mathrm{MPa} \sqrt{m}$

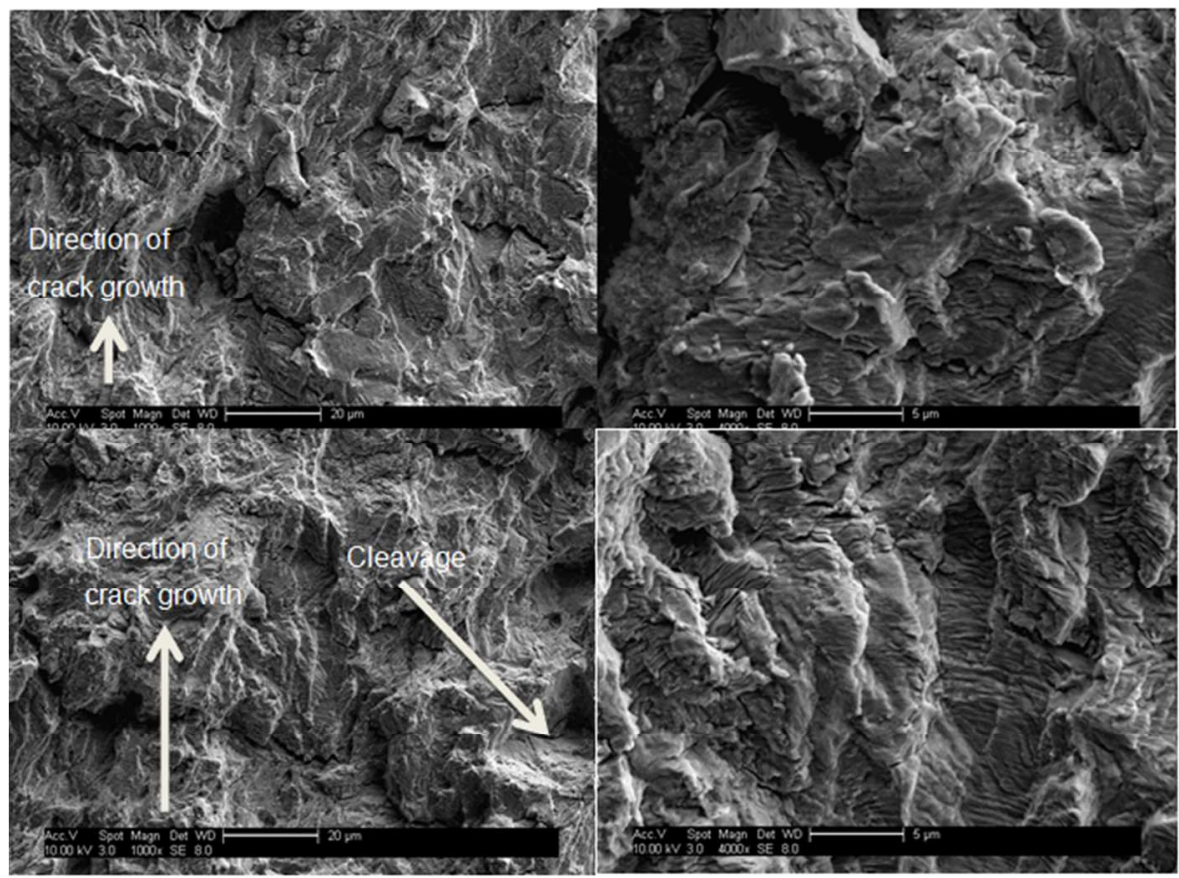

Figure 20 Transition region in HAZ material in air at $\Delta K$ between $18 \mathrm{MPa} \sqrt{\mathrm{m}}$ and $19 \mathrm{MPa} \sqrt{m}$

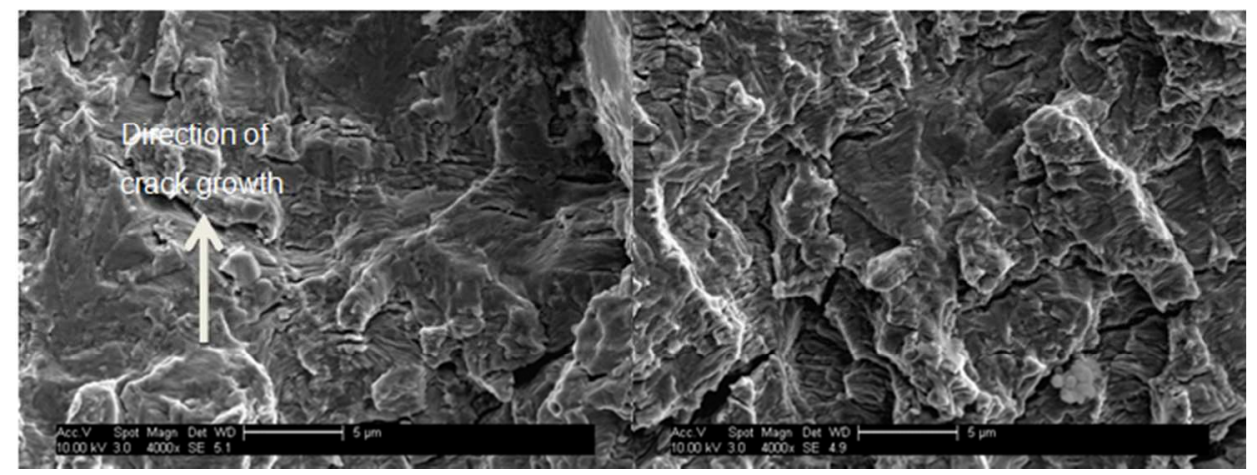

Figure 21 Mixture of ductile and brittle striation in weld material in air at $\Delta K=20 \mathrm{MPa} \sqrt{m}$ 


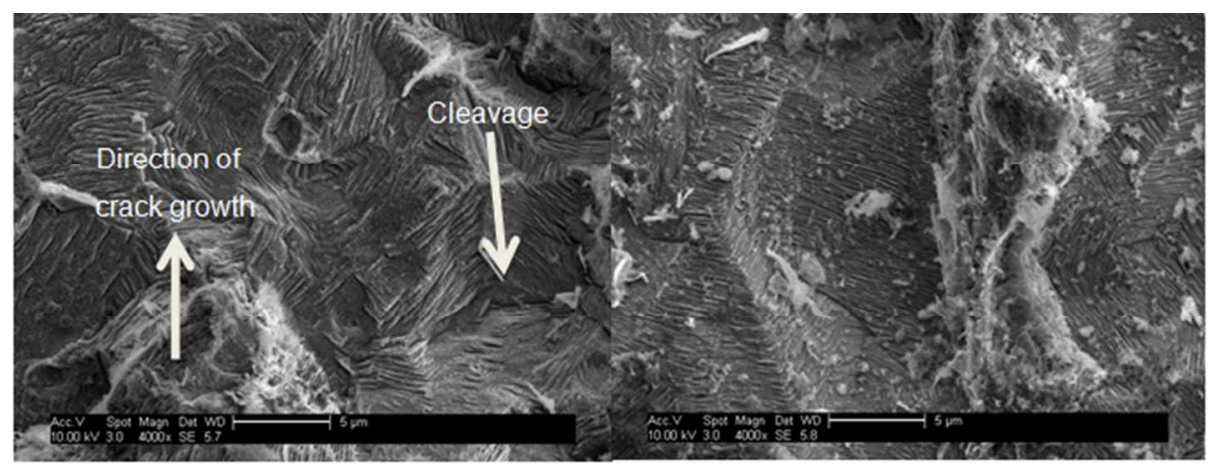

Figure 22 Ductile striations on parent material in seawater $\Delta K=19 \mathrm{MPa} \sqrt{m}$

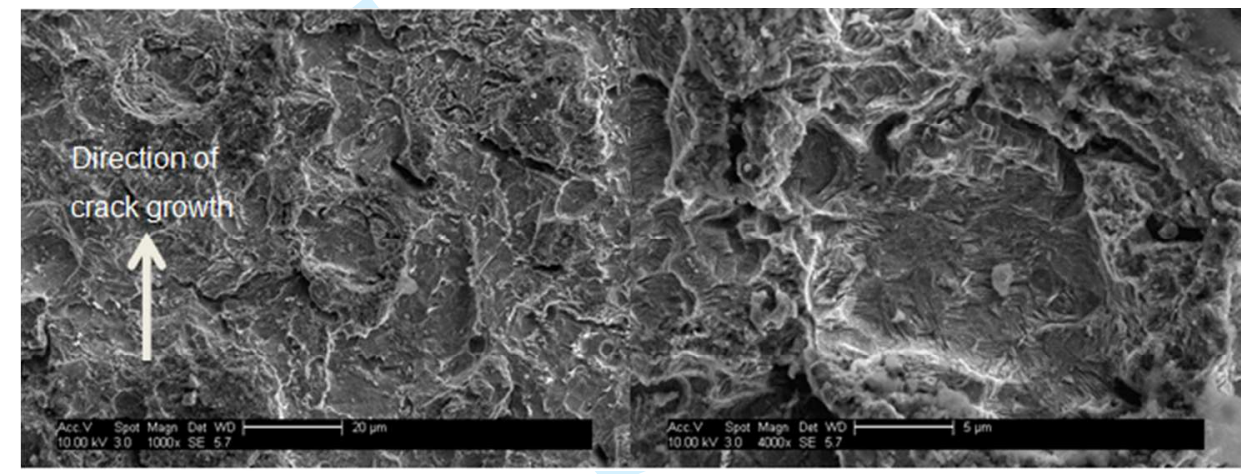

Figure 23 Mixture of brittle and ductile striation in $\mathrm{HAZ}$ materials in seawater $\Delta K=20 \mathrm{MPa} \sqrt{m}$

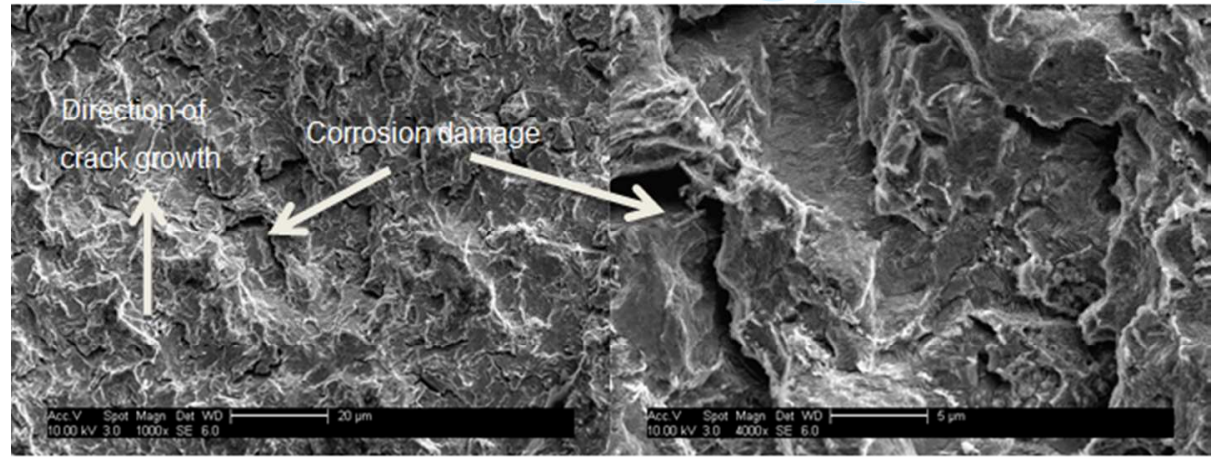

Figure 24 Brittle striations in weld materials in seawater $\Delta K=20 \mathrm{MPa} \sqrt{m}$ 

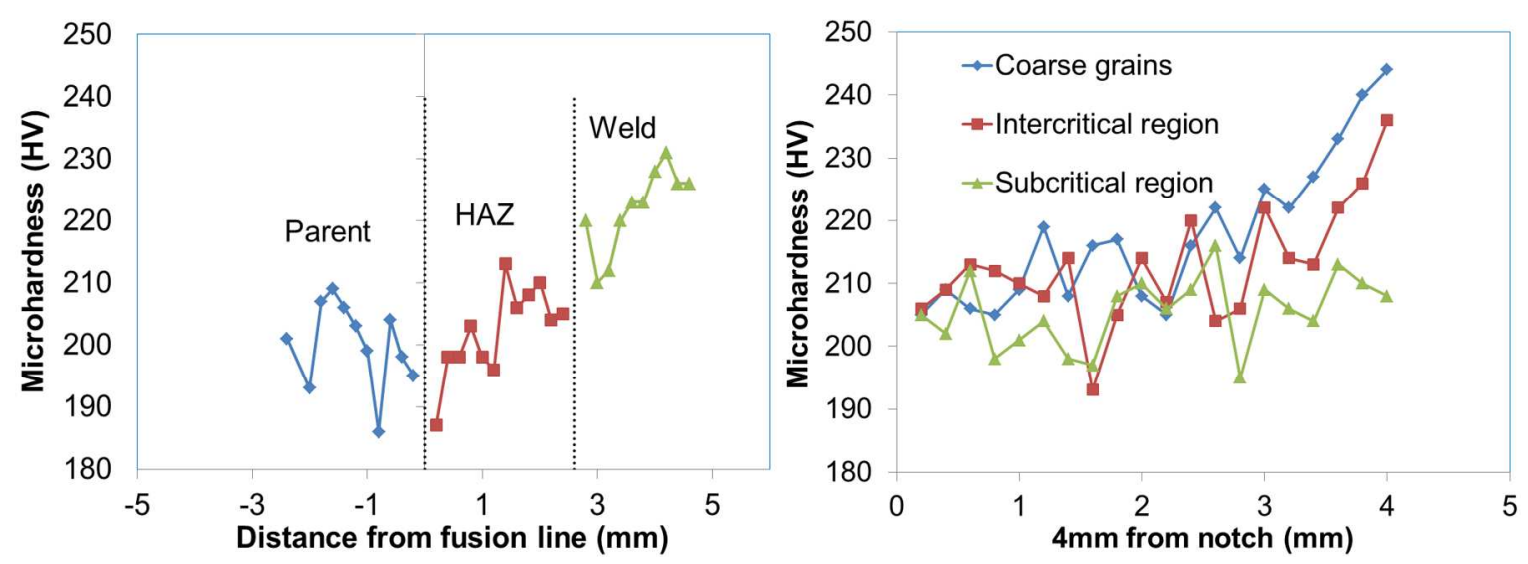

Figure 25 Vickers hardness values, left: parent to weld, right: along HAZ 